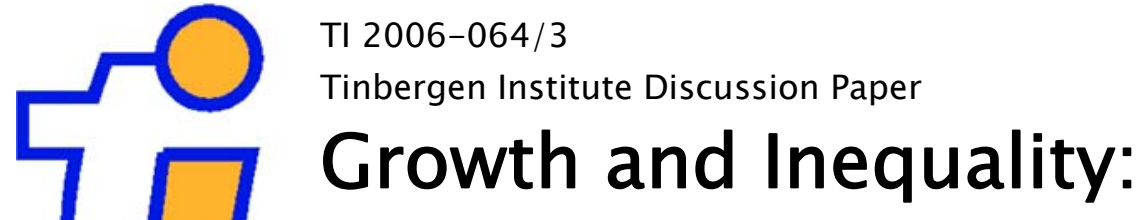 A Meta-Analysis
}

Laura de Dominicis 1,2

Henri L.F. de Groot ${ }^{1,3}$

Raymond J.G.M. Florax ${ }^{1,4}$

1 Vrije Universiteit Amsterdam,

2 Universita' degli Studi di Tor Vergata, Rome, Italy,

3 Tinbergen Institute,

4 Purdue University, West Lafayette, USA. 


\section{Tinbergen Institute}

The Tinbergen Institute is the institute for economic research of the Erasmus Universiteit Rotterdam, Universiteit van Amsterdam, and Vrije Universiteit Amsterdam.

Tinbergen Institute Amsterdam

Roetersstraat 31

1018 WB Amsterdam

The Netherlands

Tel.: $\quad+31(0) 205513500$

Fax: $\quad+31(0) 205513555$

Tinbergen Institute Rotterdam

Burg. Oudlaan 50

3062 PA Rotterdam

The Netherlands

Tel.: $\quad+31(0) 104088900$

Fax: $\quad+31(0) 104089031$

Most TI discussion papers can be downloaded at http:/ /www.tinbergen.nl. 


\title{
Growth and Inequality: A Meta-Analysis
}

\author{
Laura de Dominicis \\ Department of Economics, Universita' degli Studi di Tor Vergata, Rome, Italy.
}

Henri L.F. de Groot

Department of Spatial Economics, Vrije Universiteit, Amsterdam, The Netherlands and Tinbergen Institute, Amsterdam-Rotterdam, The Netherlands.

Raymond J.G.M. Florax

Department of Agricultural Economics, Purdue University, West Lafayette, USA and

Department of Spatial Economics, Vrije Universiteit, Amsterdam, The Netherlands.

\begin{abstract}
In recent years there has been a growing interest in the impact of inequality on economic growth. Both theoretical and empirical approaches have produced ambiguous results on sign and size of this relationship. Although there is a considerable part of the literature that considers inequality detrimental to growth, more recent studies have challenged this result and found a positive effect of inequality on growth. This paper contributes to the debate by using meta-analytical techniques to describe variation in observed outcomes of the empirical studies and to identify sources of variation.
\end{abstract}

JEL codes: O11, O15, C42, C52

Keywords: Economic growth, income distribution, inequality, meta-analysis

* Corresponding author: Henri L.F. de Groot, Department of Spatial Economics, Vrije Universiteit, De Boelelaan 1105, 1081 HV Amsterdam, The Netherlands. E-mail: hgroot@feweb.vu.nl, Tel.: +31 20598 6168, Fax: + 31205986004 . 


\section{Introduction}

In recent years there has been a growing interest in the impact of income inequality on economic growth. A natural starting point is the seminal work of Kuznets (1955). The Kuznets hypothesis states that inequality rises in early stages of development and subsequently falls as economic development proceeds. This hypothesis suggests that the distribution of income deteriorates over the initial stages of development as an economy transforms from rural to urban and from agricultural to industrial. Subsequently, inequality decreases as the labour force in the industrial sector expands and that of the agricultural sector declines.

Since then several theoretical models have been proposed. In some of these models inequality is considered as detrimental to growth, whereas in others it is seen as an essential and growth-enhancing factor. ${ }^{1}$ These papers have largely focused on whether countries face tradeoffs between reducing inequality on the one hand and improving growth performance on the other, or instead whether there exists a virtuous circle in which growth leads to lower inequality, with lower inequality in turn leading to faster growth. The conclusions that have been reached in the literature have potentially important policy implications. Galor and Zeira (1993), for example, show that inequality slows economic growth in the presence of capital market imperfections and indivisibilities in human capital investments. In such a world complex policy mixes are required to simultaneously enhance growth and reduce inequality.

The relationship between inequality and growth and associated mechanisms has been investigated in a rich empirical literature. Early studies have generated a rather robust body of evidence in support of the claim that inequality reduces economic growth (e.g., Alesina and Rodrik, 1994, Persson and Tabellini, 1994, Clarke, 1995, and Deininger and Squire, 1998). These studies are based on the estimation of Barro-type of cross-country growth regressions in which a measure of inequality is added to a rich set of explanatory variables.

More recently, the original cross-country evidence has been challenged. The availability of data on the income distribution for a larger sample of countries and a longer time span has allowed researchers to explore the issue by means of more sophisticated econometric techniques. Using a panel of data over 10-year intervals, Barro (2000) finds no evidence of an overall effect of inequality on growth. Li and Zou (1998), Forbes (2000) and Castelló (2004), using a fixedeffects estimator that controls for country-specific characteristics or a dynamic GMM estimator that corrects for endogeneity, find support for the existence of a positive impact of inequality on growth. Some studies have objected that a measure of inequality based on income is a weak proxy of wealth inequality. Several other measures, based on human capital inequality or land

\footnotetext{
${ }^{1}$ Benabou (1996) and Aghion et al. (1999) provide excellent surveys of the theoretical literature on inequality and growth.
} 
distribution, have been found to have a negative effect on growth even when panel data are used (Alesina and Rodrik, 1996, Deininger and Squire, 1998, and Castelló, 2004).

The debate therefore still seems open, and no general consensus has emerged so far. It seems that the different conclusions arrived at in the various studies largely depend on the econometric method employed, the countries considered in the analyses and the employed measures for income inequality. In the present paper we aim to contribute to the discussion by presenting a quantitative synthesis of the empirical literature on the relationship between income inequality and economic growth by performing a meta-analysis. Traditional approaches of literature review largely use qualitative methods, which provide a chronological, narrative and at times critical overview of previous findings. Alternatively, meta-analysis provides an in-depth quantitative review of the existing literature, and employs statistical techniques to summarize the results of a specific set of studies (see, for example, Roberts and Stanley, 2005, for recent examples in several fields of economics).

The remainder of this paper is organized as follows. Section 2 presents a concise review of the theoretical literature and focuses on the empirical results. Section 3 provides a description of the sample used in the meta-analysis, and introduces and illustrates the technique of metaanalysis. In Section 4 the sources of heterogeneity in the effect sizes are investigated, and Section 5 presents and discusses the results of the meta-regression. Section 6 briefly concludes.

\section{Theoretical foundations and empirical evidence}

\subsection{Theoretical models}

Kuznets (1955) was among the first to speculate about the existence of a systematic relationship between the distribution of income and the development of an economy. Inequality in per capita income increases in the early stages of development, in the transition from a rural to an industrial society, and decreases when the modern structure has penetrated the entire socio-economic texture. The result is the well-known inverted U-shaped relationship between inequality and per capita income, better known as the "Kuznets curve". Nowadays the theoretical literature is less clear-cut on the shape of the relationship under consideration. The contributions are divided between those that suggest that inequality is detrimental to growth, and those stating that an initial unequal distribution of resources is a conditio sine qua non for the subsequent development of an economy.

The reasons for a positive correlation between inequality and growth are neatly summarized in Aghion et al. (1999). A first argument builds on Marxist theories and is based on the hypothesis that the marginal propensity to save of the rich is higher than that of poor people. 
If the investment rate is positively related to the saving rate (for which there is very strong empirical evidence, e.g. Feldstein and Horioka, 1980), and investment and growth are positively correlated (for which there is also strong evidence established in the rich empirical growth literature), more unequal economies are likely to grow faster. Second, in the presence of investment indivisibilities and large sunk costs, and without a well-functioning capital market, a concentration of wealth is essential for setting-up new activities. The last argument rests on the trade-off between equity and efficiency and its relation with workers' incentives. If output depends on the work effort of economic agents, an egalitarian distribution of wages might discourage workers them from putting in additional effort and hence diminish the efficiency of the production system (e.g., Mirrlees, 1971)

Theoretical contributions negatively relating income inequality to economic growth can be grouped into three broad categories based on whether they use political economy arguments, socio-political arguments or credit market imperfections arguments. Within the political economy framework, income distribution affects growth negatively via the distortions induced by the government. The more the distribution of income is concentrated within a society, the more its government is tempted to introduce distorting redistributive measures, ultimately resulting in a contraction of capital investments (often the main target of taxation) and subsequently economic growth. Bertola (1993), Persson and Tabellini (1994) and Alesina and Rodrik (1994) have developed distinct models that establish a trade-off between inequality and growth through the joint effects of a political and an economic mechanism. Redistributive government expenditure and taxation increase as inequality increases (political mechanism). As a consequence, growth decreases as fiscal distortions increase (economic mechanism). According to the socio-political approach (Alesina and Perotti, 1996) a highly skewed distribution of resources induces people to engage in social activities outside the normal markets, such as crime, revolutionary activities, and violent protests. This, in turn, introduces uncertainty and mistrust towards the economic system and discourages investments and capital accumulation, and in the long run slows down the process of economic growth (e.g, Zak and Knack, 2001). The credit market imperfection arguments stress the impact of inequality on the ability of individuals to accumulate physical and human capital. Aghion et al. (1999) show that if (i) there are decreasing returns with respect to individual capital investments, and (ii) credit imperfections imply that individual investments are an increasing function of initial endowments, then inequality will be detrimental to growth by concentrating investment in the hands of fewer richer people (with a lower marginal return to investment). Similarly, Galor and Zeira (1993) show that in the presence of borrowing constraints the initial distribution of resources matters for the accumulation of human capital. In 
situations in which the distribution of wealth is highly unequal, and people cannot borrow freely because of market imperfections, fewer individuals are able to invest in human capital, and this results in a lower growth rate. Within the credit market imperfection literature, education and fertility are two important factors that may affect growth in an opposite direction. While investments in education affect growth positively, societies with high fertility rates are often associated with low rates of economic growth. In a joint education-fertility framework, Galor and Zang (1997) formalize the link between fertility and schooling decisions and their impact on growth. Given the distribution of income, a higher rate of fertility means that the family has fewer resources to invest in education, which has a contracting effect on growth. A theoretical model where the trade-off between inequality and growth works through the channel of fertility decisions demonstrates that economies with a less equitable income distribution experience higher fertility differentials, invest less in human capital, which in turn weakens the process of development (de la Croix and Doepke, 2003).

Recently, Galor and Moav (2004) have provided a unified theory in which the relationship between the distribution of income and growth is not stable over time, but depends on the stage of development in a country. In early stages of industrialization, there is a positive impact of inequality on economic growth. In this phase, the accumulation of physical capital is the prime engine of growth and it is promoted by disparities among individuals (for reasons indicated above). Once the economy has passed this initial development phase, the accumulation of human capital becomes the prime engine of growth and a more egalitarian distribution of resources allows more people to invest in education. At this stage, in the presence of credit constraints, access to education is easier if wealth is spread more equally across individuals, and policy decisions should therefore be geared towards reducing income inequality.

\subsection{Empirical contributions}

The previous discussion suggests a clear division of opinions in the theoretical literature. Also within the empirical literature results are mixed and they show a similar divide between those who find a negative effect of inequality upon growth, those who find a positive relationship and those who find a non-linear effect. The differences in the results can be largely attributed to four factors: differences in data quality, the time period covered, the cross-sectional sample coverage and the use of different estimation methods.

Income inequality can be measured in several ways. One of the most popular measures is the Gini coefficient, in particular for studies performed after 1996. Technically speaking, the Gini coefficient measures the extent to which the income among households within an economy 
deviates from a perfectly equal distribution. An index of zero represents perfect equality, while a value of 100 (or 1, when the statistic varies on a 0-1 scale) means 'perfect' inequality, viz. all income is in the hands of one household. In 1996, Deininger and Squire compiled a crosscountry dataset in which they put together a much larger and comprehensive sample of data on income distribution than hitherto available. ${ }^{2}$ Their sample contains around 680 high-quality observations $^{3}$ pertaining to different periods for 108 countries of the Gini coefficient. The dataset constitutes a non-negligible improvement in terms of reliability of data, especially if compared to those used in previous studies, although the dataset still has its limitations. ${ }^{4}$

Along with the Gini coefficient, researchers have used other measures of inequality such as the share in incomes of a particular quintile (e.g., the bottom 20 percent), the ratio in incomes of different groups (e.g., the ratio in incomes of the top vs. the bottom), or measures belonging to the family of generalized entropy measures. ${ }^{5}$ For the meta-analysis, we prefer to restrict our analysis to studies that use the Gini coefficient in order to ensure the highest level of comparability across different estimates of the impact of inequality on growth. Moreover, several studies report that, with only few exceptions, all measures of income inequality are highly correlated (Clarke, 1995, and Nahuis and de Groot, 2003).

The standard procedure for estimating the impact of inequality upon growth is to assume a simple linear relationship between the two variables. The growth rate of per capita income is regressed on a series of explanatory variables used to explain the differences in growth rates among countries plus a measure of income inequality:

$$
\left(\ln y_{i, t}-\ln y_{i, t-\tau}\right) / \tau=\beta \ln y_{i, t-\tau}+\gamma_{i, t-\tau}+X_{i, t-\tau} \psi+\varepsilon_{i, t},
$$

where the dependent variable is the average annual growth rate of GDP per capita, $y_{i, t}$ is GDP per capita of country $i$ at time $t, I$ is a measure of income inequality, $X_{i, t}$ a vector of other explanatory variables (including a constant), $\tau$ is the length of the period (in years) and $\varepsilon_{i, t}$ is the error term that is typically assumed to be well-behaved.

Studies based on cross-country regressions typically report a negative and statistically

\footnotetext{
2 The Deininger and Squire dataset is available at www.worldbank.org. For additional information on the dataset see Deininger and Squire (1996).

${ }^{3}$ In order to achieve "high-quality" standards the inequality measures have to fulfil a series of conditions: they must be based on household surveys, the population covered must be representative of the entire country and the measure of income (or expenditure) must be comprehensive, including income from various sources, such as selfemployment, non wage earnings, and non monetary income (Deininger and Squire, 1996).

${ }^{4}$ Atkinson and Brandolini (1999) and Székeli and Hilgert (1999) argue that, in the cases of OECD and Latin American countries, the dataset is plagued by serious problems of data comparability and quality.

${ }^{5}$ For an exhaustive discussion on inequality measures see Cowell (1995).
} 
significant relationship between initial income inequality and growth. The negative coefficient is stable and holds for different measures of inequality, samples of countries and time periods (see Alesina and Rodrik, 1994, Clarke, 1995, and Persson and Tabellini, 1994).

One of the main critiques to this kind of evidence is that cross-country estimates may be biased due to omitted variables in the model. Factors such as technology, climate, institutions and any other variable specific to a particular country may be important determinants of growth and may be correlated with the explanatory variables considered in the model. The inclusion of such covariates in the regression is generally rather cumbersome as most of these variables are difficult to observe in reality or degrees of freedom are insufficient to determine their influence. By assuming that those variables are constant over time and using longitudinal instead of crosssection data, one can control for the influence of missing covariates making additional assumptions with respect to the error term of the model. A general specification of the error term is:

$$
\varepsilon_{i, t}=\xi_{t}+\alpha_{i}+\mu_{i, t},
$$

where $\xi_{t}$ is a time specific effect, $\alpha_{i}$ reflects the characteristics of every country which are constant over time and $\mu_{i, t}$ collects the remaining part of the error which varies over time and over countries. Equation (1) can then be rewritten as:

$$
\ln y_{i, t}=\widetilde{\beta} \ln y_{i, t-\tau}+\widetilde{\gamma}_{i, t-\tau}+X_{i, t-\tau} \widetilde{\psi}+\widetilde{\xi}_{t}+\widetilde{\alpha}_{i}+\widetilde{\mu}_{i, t},
$$

where $\widetilde{\beta}=\tau \beta+1, \widetilde{\gamma}=\tau \gamma, \widetilde{\psi}=\tau \psi, \widetilde{\xi}_{t}=\tau \xi_{t}, \widetilde{\alpha}_{i}=\tau \alpha_{i}$ and $\widetilde{\mu}_{i, t}=\tau \mu_{i, t}$. This regression is a general panel analogue to the cross-section regression in equation (1). There is a variety of different techniques to estimate equation (3). The assumptions made about the error term and its correlation with the explanatory variables influence the choice of the estimation method. The standard methods for panel estimation are the fixed or random effects estimators. The vast majority of panel data growth studies uses a fixed rather than a random effects estimator. The latter requires that the country-specific effects $\alpha_{i}$ are distributed independently of the explanatory variables, and this requirement is violated by construction for a model as in equation (3), given the dependence of $\ln y_{i . t}$ on $\alpha_{i}$. The fixed effects model does allow the unobserved individual effects to be correlated with the included variables, but it comes at a cost. Temple (1999, p. 132) observes: " $[\ldots]$ Too often researchers use fixed effects approaches to analyze the effect of 
variables that are fairly constant over time, or that will affect growth only in the long run". The fixed effects method disregards persistent effects and can produce misleading results in the case where most of the variation is cross-sectional, which is not unlikely for a variable related to the income distribution. In addition, a problem with both fixed as well as random effects is that equation (3) contains a lagged dependent variable, which undermines the assumption of strict exogeneity of the explanatory variables. Faced with these econometric problems, most of the studies have used GMM estimators. The GMM estimator developed by Arellano and Bond (1991) works by first-differencing each variable to eliminate the country-specific effect and then uses all possible lagged values of the explanatory variables as instruments to alleviate the problem of endogeneity. However, this approach is also sensitive to critique if used to model the casual relationship between inequality and growth. The use of a lagged explanatory variables in the regression is likely to perform badly when the variables are highly persistent, because in that case lagged levels are weak instruments for first differences (Temple, 1999). The system GMM estimator proposed by Arellano and Bover, and Blundell and Bond have been recently used by Castelló (2004) to partially solve the problem. The idea of the method is to combine a regression equation in levels with regression equations in differences in a system of equations. In this estimator, not only lagged levels are used as instruments for first differences, but also first differences are used as instruments for levels. ${ }^{6}$

The application of panel data models has changed the view on the influence of inequality on growth. Li and Zou (1998), Forbes (2000) and Deininger and Olinto (2000) all use panel data over 5-years intervals and find evidence of a positive and significant impact of income inequality on growth. ${ }^{7}$ However, the statistical significance for the income inequality coefficient disappears when the system GMM estimator is adopted (Castelló, 2004). The fixed-effect estimator has been heavily criticized by Barro (2000), who maintains that it exacerbates the bias due to measurement error. Using panel data over 10-year intervals and a three-stage least square estimator that treats country-specific effects as random, no significant relationship between inequality and growth can be detected for the entire sample of countries. However, after considering separately the relationship for rich and poor countries, the results show evidence of a negative relationship for poor countries and of a positive relationship for rich countries.

Some authors claimed that the lack of consensus in the findings may be due to the fact that most of the empirical studies - if not all - estimate a linear model, whereas the correct

\footnotetext{
${ }^{6}$ Monte Carlo experiments (Blundell and Bond, 1998) reveal that this estimator is more robust than the ArellanoBond method in presence of highly persistent series, which are likely in the case of income inequality measures.

${ }^{7}$ While Li and Zou (1998) use a fixed effect model to estimate the relationship, Forbes (2000) and Deininger and Olinto (2000) estimate a panel data model using the GMM proposed by Arellano and Bond (1991).
} 
functional form might be non-linear (Banerjee and Duflo 2003). The authors argue that allowing for the non-linearity of the effect of inequality, a change in any direction of the income distribution may be detrimental to growth. In addition, some doubts have been cast over the use of a statistical measure based on income as a proxy for wealth inequality. Alesina and Rodrik (1994) and Deininger and Squire (1998) use data on land inequality to estimate the model. The results show that the negative impact of land inequality on growth (in a cross-section analysis) is more robust than that of income inequality. Castelló (2004) estimates a dynamic panel model where income inequality and human capital inequality are jointly considered. He finds that in contradistinction to results for income, the negative effect of human capital inequality on growth holds not only in the long-term, as analyzed in cross-section regressions, but also in the shortterm.

A recent study investigates the importance of the shape of the income distribution as a determinant of economic growth and emphasizes how inequality for different sections of the income distribution can affect growth differently (Voitchosky, 2005). The central hypothesis of the paper is that the positive and the negative effect of inequality on growth are associated with inequality in different parts of the income distribution. Based on a dataset consisting of industrialized countries, the author finds support for the existence of a positive relationship in the upper tail of the distribution, while evidence for a negative mechanism is reported for the lower tail of the distribution.

\section{Meta-analysis}

Nowadays the empirical evidence on almost any research topic grows at an exponential rate. Traditional approaches of literature review typically use qualitative methods to analyze previously determined empirical results. However, especially in the case of a rapidly expanding literature, the reviewer is faced with increasingly complex and arbitrary selection criteria. Meta-analysis provides the tools to perform an in-depth quantitative review of the existing literature, and employs statistical techniques to summarize the previously established results. Although the use of meta-analysis has problems of its own (for instance, operationalization of study differences, and model uncertainty), it constitutes an appropriate complement to literature reviews and adds to our understanding of differences in empirical results.

In 1976, Eugene Glass coined the term meta-analysis as "the analysis of analyses". Ever since, a large number of meta-analyses has been carried out in the medical and social sciences, where the experimental set-up of the research has made its adoption more straightforward. However, more recently, meta-analytical techniques have been used in other fields of research as 
well, including in economics. We find applications in, for example, macroeconomics (Stanley, 1998, 2004, Görg and Strobl, 2001, Rose, 2004, and Abreu et al., 2005), labour economics (Card and Krueger, 1995, Ashenfelter et al., 1999, and Longhi et al., 2005), agricultural and environmental economics (van den Bergh et al., 1997, Brouwer et al., 1999, Travisi et al., 2005, and Brander et al., 2006) and transport economics (Button, 1995, Button and Kerr, 1996, Button and Rietveld, 2000, Wardman, 2001, de Blaeij et al., 2003).

In what follows we apply meta-analytical tools to combine, summarize and model the results found in the empirical literature considering the effect of income inequality on growth. As a first step we searched the Economic Literature Index (EconLit) ${ }^{8}$ for any reference on "growth" and "inequality". Furthermore, we reviewed the web pages of institutes engaged in research on income distribution and world poverty reduction. ${ }^{9}$ Our search led to 1792 results. We excluded purely theoretical articles, papers in languages other than English, and we restricted our sample to studies that make use of the Gini index as a measure of inequality. After screening the full list of articles for the above criteria, we were left with 22 studies with a total of 254 estimates of the coefficient associated with the Gini index. ${ }^{10}$

Table 1 illustrates the composition of our meta-sample and reports for every study the year of publication, whether the paper has been published or not, its contribution to the database in terms of number of observations and the average value of the estimates.

[Table 1 about here]

While cross-country studies typically find a negative relationship between the two variables, studies based on pooled data tend to report a positive coefficient. Panel data estimations differ from cross-section analyses in that they study the variation of inequality within a country over time, with time periods in most of the cases of 5 years. ${ }^{11}$ Cross-section studies on the other hand are looking at differences in the relationship between income inequality and growth across countries over a longer time period, usually 25 or 30 years.

Figure 1 presents the frequency distribution of the point estimates included in the meta-

\footnotetext{
8 The Economic Literature Index (www.econlit.org), published by the American Economic Association, provides bibliographic references of a wide range of economics-related literature. The number of journals indexed in EconLit has grown from 182 periodicals in 1969 to over 400 journals today. In March 2006, the database contained more than 730.000 references, increasing with around 30.000 records per year.

9 World Bank Poverty Net (www.worldbank.org/poverty) and Luxemburg Income Studies (www.lisproject.org).

10 The estimates as reported by the primary studies were not directly comparable. Data on growth rates and Gini coefficients can be expressed in percentage points. When both growth rates and Gini are expressed in the same unit (percentage points) the estimates can be used without transformation. When the units did not conform appropriate transformations were made.

${ }^{11}$ Barro (2000) is the only study at the country level using a panel based on sub-periods of 10 years. Panizza (2002), using regional data for the US, employs a panel dataset with sub-periods of 10 and 20 years.
} 
sample. A remarkable feature that emerges is the large heterogeneity in the sample, with around $40 \%$ of the values showing a negative value, and an equal amount of estimates that exhibits a value close to zero. Only the remaining $20 \%$ of the estimates are positive.

\section{[Figure 1 about here]}

We adopt meta-analytical techniques to describe the differences in the empirical findings and subsequently to model the resulting heterogeneity as a function of variations in research design and countries and time periods considered. At first, we consider the question whether the estimates represent a single underlying effect (population effect) driving the mechanism that links inequality to growth. A consolidation method frequently adopted in meta-analysis is to derive an overall value from the meta-sample by pooling all the estimates and deriving an overall summary statistic. Two approaches are widely used in meta-analysis, known as the fixed and random effects method.

The fixed effect method assumes that there is no heterogeneity among study results and, when differences are present, they are entirely due to study-level sampling errors. It is equivalent to saying that all effect sizes are equal, i.e., $\theta_{1}=\theta_{2}=\ldots=\theta_{k}=\theta$, where $\theta$ is the true common underlying effect, or population effect size. The pooled estimate of the effect size is given by:

$$
\bar{T}=\frac{\sum_{i=1}^{k} w_{i} T_{i}}{\sum_{i=1}^{k} w_{i}},
$$

where $i=1, \ldots, k$ are independent observations of the effect sizes $T_{i}$ and $w_{i}$ is a weight assigned to the $i$ th study. ${ }^{12}$ The statistic is a weighted average of all effect sizes in the sample, with weights inversely proportional to the precision of the estimates. The weights are defined as $w_{i}=1 / v_{i}$ where $v_{i}$ is the estimated variance of the effect size.

The random effect method assumes that every study estimates a different population effect size, randomly drawn from a normal distribution with fixed mean and variance. Under the random effect hypothesis the pooled estimate has two components, viz. the true effect size and a value that represents other sources of variability which are assumed to be randomly distributed:

\footnotetext{
12 Hedges and Holkin (1990) show that the weights that minimize the variance of the statistic are inversely proportional to the square of the standard errors reported in the primary studies. The method is therefore also referred to as the "inverse variance" method.
} 


$$
T_{i}=\theta_{i}+\varepsilon_{i}
$$

In this situation, the variance associated with each effect size has two components: one associated with subject-level sampling level (as in the fixed effect model), and a second component associated with the random effects variance. The inverse variance weights are now given by $w_{i}=1 / v_{i}+\tau^{2}$, where $\tau^{2}$ is the estimate of the between-studies variance component. For further details we refer to Sutton et al. (2000).

We have calculated the pooled estimates of the effect sizes in our database. The fixed effect estimates show a value of -0.004 , while the random effect estimate model results in a combined value of -0.024 . The existence of a trade-off between income inequality and economic growth seems to be reinforced by these pooled estimates. In both cases, the null hypothesis of a coefficient different from zero is significant at the $1 \%$ level.

A $Q$-test on the pooled estimates can be performed to check for the presence of heterogeneity among estimates. If $Q$ exceeds the critical value of a $\chi^{2}$ distribution with $n-1$ degrees of freedom, the null hypothesis of homogeneity is rejected. This indicates a heterogeneous distribution and hence the variability of the effect sizes is greater than what is expected on the basis of sampling error alone. ${ }^{13}$ Algebraically, the $Q$-statistic has the following form:

$$
Q=\sum_{i=1}^{k} w_{i} T_{i}^{2}-\frac{\left(\sum_{i=1}^{k} w_{i} T_{i}\right)^{2}}{\sum_{i=1}^{k} w_{i}}
$$

In our sample, the $Q$-statistic equals 1433.54 which, with 253 degrees of freedom, shows that the null hypothesis of homogeneity is rejected with a $p$-value $<0.001$.

One of the major advantages of meta-analysis is the possibility to explicitly test for the presence of 'publication bias'. The studies for a meta-analysis are usually chosen through a literature review. In these circumstances an inherent selection bias may arise, since for example, studies may tend to be published more readily if they show statistically significant results, or deemed to be more "interesting" in terms of the impact of their outcomes. The bias is oftentimes associated with what is called the file-drawer effect because the unpublished results

\footnotetext{
13 Note that the test assumes independence among effect sizes and is not fully adequate in the case of multiple measurements (Sutton, 2000).
} 
are imagined to be tucked away in researchers' file cabinets. Publication bias is a potentially severe impediment to combining the statistical results of studies from the collected literature. Researchers have developed several tools to explore the potential presence of publication bias, including funnel plots, meta-significance tests, the trim and fill method and various parametric and non-parametric approaches (see Stanley, 2005, for a comprehensive review of the methods available).

A popular graphical test for detecting the presence of publication bias is the funnel plot (Egger et al. 1997). The funnel plot compares the effect size - in our analysis the estimated coefficient of the impact of inequality on growth - against some measure of its accuracy, such as the sample size or the associated standard error. In theory, this plot should show a 'funnel' shape centred around the true overall mean (the population effect size). Publication bias may lead to asymmetrical funnel plots. It is, however, important to realize that publication bias is only one of a number of possible causes of funnel plot asymmetry. The funnel graph in Figure 2 plots on the vertical axis the estimated coefficients associated with the inequality measure in the collected literature and on the horizontal axis the associated estimated standard errors. The horizontal line in the funnel plot indicates the pooled fixed effects estimate (based on the inverse-variance weighting method) while the sloping lines indicate the expected 95\% confidence intervals assuming no heterogeneity between studies. The funnel plot appears clearly not symmetrical, with a tendency of overrepresentation of results reporting a negative impact of inequality on economic growth, although the pooled effect size is very close to zero.

[Figure 2 about here]

However, a funnel plot is based upon a subjective and visual inspection of the relationship between the effect size and its precision. Egger et al. (1997) proposed a test for detecting asymmetry of the funnel plot. The test detects funnel plot asymmetry by determining whether the intercept deviates significantly from zero in a regression of the standardized effect estimates against their precision. The estimated intercept for our sample is -0.095 , with an associate $p$ value $<0.001$. Sutton et al. (2000) suggest that the resulting slope may be interpreted as a rough estimate of the true effect size after correcting for publication bias. In our sample the coefficient associated with the slope of the regression is 0.002 , which lends support to the result of the panel data studies in the sample that the alleged existence of a negative impact of inequality on growth may be erroneous. 
We can derive some preliminary conclusions from the above. First, by pooling the estimates in our sample, regardless whether we use the fixed or the random effects model, we find that inequality and growth are negatively correlated. However, after testing for publication bias, we observe that negative values are overrepresented in the collected literature, and the conclusion of a trade-off between inequality and growth may therefore be misleading. In addition, the results of the $Q$-test seem to suggest that there is still some variation that we did not account for. This variation may be partly related to observable differences. In order to reach a definitive conclusion, it is necessary to perform a multivariate analysis, since the variation found in the literature may be related to identifiable variation in study characteristics (i.e., estimation methods, quality of the data, sample of countries and time periods considered in the primary studies).

\section{Meta-regression}

\subsection{Traditional approaches in meta-analysis}

Meta-regression is a tool offered by meta-analysis to model the heterogeneity in the findings of a body of studies, in particular when one is in some way aware that this variation is due to differences in study-to-study characteristics. Technically speaking, it is a regression where "the dependent variable is a summary statistic, perhaps a regression parameter, drawn from each study, while the independent variables may include characteristics of the method, design and data used in these studies" (Stanley, 2001, pp. 132-133).

Two regression models widely used to control for heterogeneity in study results are the fixed and the mixed effects model. The fixed effects model assumes that the variability among the effect sizes can be fully explained by a series of moderator variables that account for differences in study characteristics:

$$
T_{i}=\beta_{0}+\beta_{1} x_{i, 1}+\ldots+\beta_{k} x_{i k}+\varepsilon_{i}
$$

where $i$ refers to the estimated effect sizes $(i=1,2, \ldots, I), k(=1,2, \ldots, K)$ indexes the moderator variables and $\varepsilon_{i} \sim N\left(0, \sigma_{i}^{2}\right)$. As compared to the pooled fixed effect estimate - where the null hypothesis is the existence of one single effect size - the effect sizes are now allowed to be different for different groups of studies or estimates with specific characteristics. It is, however, assumed that all the variation is systematically and fully predictable by a number of 
covariates. ${ }^{14}$

In the mixed effect model the variability beyond sampling error is derived partly from systematic factors - as in the fixed effect model - and partly from random sources:

$$
T_{i}=\beta_{0}+\beta_{1} x_{i, 1}+\ldots+\beta_{k} x_{i k}+\mu_{i}+\varepsilon_{i},
$$

where $\varepsilon_{i} \sim N\left(0, \sigma_{i}^{2}\right)$ as before, and $\mu_{i} \sim N\left(0, \tau^{2}\right)$. The mixed effects model allows for the presence of residual heterogeneity by assuming that the underlying effects follow a normal distribution around the effects predicted by the covariates. Equation (8) therefore presents two components in the error term that are jointly considered by adding the variance of the random term inside the weights used in the estimation (see, e.g., Sutton et al., 2000, for details).

It is oftentimes questionable whether a fixed or a mixed effect model is the most appropriate method to investigate the heterogeneous distribution of effect sizes. The fixed effect model is quite restrictive, as it assumes that all heterogeneity is perfectly observable. In spite of that it has more statistical power to identify systematic between-study differences. On the other hand, the mixed effect model relaxes the assumption that all heterogeneity is fully observable, but does so at the cost of a loss of statistical power in identifying moderator effects. The mixed effect model has a further drawback. It assumes additivity of the effect size's variances. Most of the meta-analysis carried out in economics are characterized by multiple measurement of the effect size coming from the same study, for which the lack of independence among estimates and the nested structure of the error term makes traditional estimation procedures such as the fixed and mixed effects model less suitable.

\subsection{Hierarchical level models}

Data used in meta-analysis are characterised by an inherent hierarchical structure, with observations clustered within studies. The models presented in the previous section all assume independence between estimates. If primary studies report multiple measurements of the effect size, the assumption that the observations are independent replications of a stochastic process

\footnotetext{
${ }^{14}$ The estimation is performed by mean of weighted least square algorithms, with the weights inversely proportional to the precision of the estimates (i.e., the square of the standard errors reported by the primary studies). It is important to note that the weighted least squares performed by standard statistical packages is based on a model that is slightly different from the one used in meta-analysis, because the meta-analysis model assumes that the variation is entirely explained by the covariates. While the coefficients are still valid, the reported standard errors require to be adjusted according to:

$$
\left(S E_{a d j}-S E_{w / s}\right) / \sqrt{M S E},
$$

where $S E_{a l j}$ is the adjusted standard error, $S E_{w l s}$ is the standard error as reported for the weighted least squares estimate, and MSE is the "residual" mean square from the analysis of variance for the regression (Sutton et al., 2000, p. 94).
} 
can be easily criticised. The existence of a non-zero within-study correlation means that conventional estimation procedures (i.e., OLS) lead to incorrect inferences (Goldstein, 1995). In particular, the estimated parameters are not correct and - especially when the intra-unit correlation is significant - the conventional regression procedure will tend to under-estimate the standard errors of the coefficients (Bateman and Jones, 2003). Most analytic techniques require independence of observations as a primary assumption for the analysis. Because this assumption is violated in the presence of hierarchical data, ordinary least squares regression produces standard errors that are too small. In turn, this leads to a higher probability of rejection of the null hypotheses.

Researchers have generally adopted two approaches to deal with multiple measurements within studies. The first approach considers the use of a single effect size value for every study. The value can be an aggregate statistic (i.e., average or median) or - alternately - one observation randomly selected from the entire set of estimates for a specific study. The method is not always the most appropriate as it does not use all information contained in the primary studies. In the second approach all measurements are individually included in the analysis and treated as weighted independent replications, with weights proportional to the number of estimates contained in the study (Rosenthal 1991, p. 27). The weighting scheme makes it possible to account for the fact that studies with many measurements may have a larger impact on the results. However, none of these approaches considers explicitly the hierarchical nature of the data. Multilevel linear models (Goldstein, 1995) can be applied to control for the presence of within-study dependence. This class of models has frequently been used in epidemiology and education research in which the clustering of the units within groups is more evident (for instance, patients are nested within treatment groups, students are nested within schools).

Raudenbush and Brik (2002) have pointed out that meta-analysis may be viewed as a special case of the two-level hierarchical model. In each study, a within study model is estimated, and a second level, or between study model, is added to explain the variation in the within study parameters as a function of the differences between the studies. So far, multilevel models have been used in meta-analysis mostly in the field of health studies (Beacon et al., 1999, Rutter and Gatsonis, 2001) and education (Goldstein et al., 2000). In economics few meta-analysis have been carried out in which the hierarchical structure of the data is explicitly incorporated in the regression model (Brouwer et al., 1999, Bijmolt and Pieters, 2001, and Bateman and Jones, 2003).

In a two-level hierarchical regression framework, a general model for meta-analysis with multiple measurements within studies leads to the following formulation, where the effect size is regressed over a set of explanatory variables plus an error term that now consists of two distinct 
components:

$$
T_{i j}=\beta_{0}+\beta_{1} x_{i, 1}+\ldots+\beta_{k} x_{i k}+\mu_{0, j}+\varepsilon_{0, i j},
$$

where $i$ indexes the individual observations nested in study $j, \boldsymbol{\varepsilon}_{0, j}$ represents the error term at measurement level, and $\mu_{\mathrm{o}, j}$ is the error term at the study level shared by all measurements within the same study. ${ }^{15}$

We perform a multilevel regression analysis in order to investigate the variability in the estimated coefficients of the inequality measure in the empirical literature so far discussed. The estimates reported in the primary studies are regressed over a set of moderator variables that are chosen to control for differences in study characteristics. The potential dependency problem induced by the presence of multiple measurements of the effect size is explicitly taken into account by imposing a nested structure of the error term as in equation (9). For the sake of comparability, the results for the random effect model are also reported.

\section{Meta-regression results}

Table 2 presents the results of the regressions for the mixed effect model and the hierarchical linear model. ${ }^{16}$ For the interpretation of the results we will refer only to the hierarchical model. Inspection of the standard errors of the random effect model confirms that in the presence of intra-study correlation, standard econometric techniques that assume independence among observations tend to underestimate the errors associated with the estimated coefficients.

Following the discussion of potential sources of heterogeneity in Section 2, we hypothesize that the variation in empirical results is at least partly observable and attributable to differences in [1] estimation methods, [2] data quality, [3] the time period covered and [4] the geographical coverage of the primary studies.

[Table 2 about here]

As a first step, we investigate whether the use of pooled data instead of cross-sectional data leads

\footnotetext{
${ }^{15}$ See Goldstein (1995) for a methodological discussion of the two-level hierarchical model. The inadequacy of the OLS estimator in presence of intra-unit correlation is also formally discussed in Section 2.8.

${ }^{16}$ The estimation of the multilevel linear model has been performed using the software HLM6 developed by Raudenbush and Kirk. The precision of the estimates has been accounted for through the V-Known routine. The V-known option is a general routine that can be used for applications where the level- 1 variances are known. For details see Raudenbush and Kirk (2002).
} 
to different results. We have defined a dummy labelled pooled which has a value equal to one when the primary study estimate is based on the use of pooled data. The coefficient is positive and statistically significant at the $1 \%$ level. On average, estimates based on pooled data show a value of the Gini coefficient that is 0.066 higher. The pooling of the data allows researchers to increase the size of their sample and to control for country-specific effects without facing the problem of loosing degrees of freedom. We find that once cross-country variation is controlled for in the primary studies, the estimates show a positive relationship between inequality and growth which is a result also found in studies conducted at regional level (Panizza, 2002, and Partridge, 2005).

We also control for the use of different estimation methods in the primary studies. Estimates based on cross-section data are generally produced via ordinary least squares estimators. We use OLS as reference category to evaluate the impact of alternative estimators on the effect sizes. Fixed effects is a dummy equal to one when the primary study estimates the regression using a fixed effect panel estimator. After controlling for time-invariant country specific effects we find that the estimates are on average 0.051 higher. The result is highly significant even after controlling for the within-study dependence by means of the hierarchical model. Random effects is a dummy that equals one when the primary study estimates a panels model that allows the individual constant term to be randomly distributed across cross-sectional units. The coefficient is negative and significant. The result seems to confirm the fact that it is too simplistic to affirm that studies based on pooled data tend to report a positive effect of inequality upon growth. The positive sign found in the literature is most likely strongly associated with the use of a fixed effect estimator. Partridge (2005) has criticized the use of the fixed effect method to estimate the relation between income distribution and growth, as not fully appropriate to describe the behaviour of a variable such as inequality, which is highly persistent over time.

There is a fundamental problem of endogeneity in the growth regressions that needs to be addressed, because the direction of the causality between growth and inequality is not well defined. It is plausible to assume that income inequality is jointly determined with the economic growth rate. If the explanatory variables are endogenous and thus correlated with the error term, the OLS/Fixed-effects coefficient estimate is biased and inconsistent. The fact that the explanatory variables are dated at the beginning of the growth period naturally minimizes the problem of endogeneity. But when the variables are highly persistent - as in the case of the Gini coefficient - the problem of endogeneity may still persist. Endogeneity is a dummy variable equal to one when the primary study controls for the potential problem of reverse causality by using instrumental variables in the cross-section studies or GMM estimators in studies based on 
pooled data. From our results the effect on the estimates seems to be not significantly different from zero.

A common concern in the literature is that data on income distribution are likely to be plagued by measurement error. When a variable is badly measured its coefficient is biased towards zero (the so-called attenuation effect) resulting in a weaker impact on the dependent variable. In multivariate regression models the consequences are even more serious. The error in one of the explanatory variables not only affects the coefficient of the variable itself, but the other coefficients are biased as well, although in an unknown direction (Greene, 2000).

We checked for the effect of badly measured data of inequality in several ways. We first analysed the effect of the use of different dataset to measure income inequality. The reference category is the use of the dataset compiled by Deininger and Squire. As we want to check whether the adoption of a different dataset provokes a bias towards zero in the estimates, we have analyzed the issue separately for the estimates obtained through cross-section data, and estimates based on pooled data. Other dataset is a dummy variable that is equal to 1 when the primary study uses pooled data and does not employ the dataset compiled by Deininger and Squire. As expected, the value is negative and highly significant. When information on the Gini coefficient is drawn from a different source, the positive sign found in the studies based on pooled data declines. The variable Other dataset ${ }^{*} c-s$ is a dummy equal to one when primary studies based on cross-section data use a dataset different from the Deininger and Squire dataset. The variable is in the form of an interaction term and does not capture directly the impact of the variable on the dependent variable. In order to attain the direct impact, we have to aggregate this estimate with the estimate obtained for the variable Other dataset. Even after correcting for the interaction term we have a positive value of the coefficient (equal to 0.026). Also for the studies based on cross-section data, the adoption of a different dataset weakens the reported (negative) impact of inequality on growth, which signals a potential problem of measurement error.

The problem of the reliability of the data can also be investigated by looking at the quality of the data on income distribution used in the primary studies, without considering explicitly the primary source of the data. We have used two different dummies to signal the influence of data of low and high and low quality. For the interpretation of the results we used the studies that use data of high quality as the reference category. The results show that the estimates from the studies that use data with a mixed quality tend to produce a coefficient that is on average 0.029 points higher than the ones that adopt only high quality data. Our hypothesis that poorly measured data on income inequality may suffer of a problem of measurement error is hence corroborated. In our sample, only cross-country studies estimate the relationship by using 
data on income distribution that are not of high quality. Controlling for the use of badly measured income data results in an attenuation of the negative impact of inequality on growth. When the primary studies make use of data of low quality, the estimates show on average an estimated correlation that is 0.036 points lower. A clear conclusion cannot be recovered from this result because only one study in our database explicitly estimates the model with low quality data (Forbes, 2000).

The paucity of long time series on income distributions has induced researchers to replace the measure of inequality measured at the beginning of the period with the average value over the whole period. Experience suggests that within a country inequality does not change substantially over time. The variability of the index is even lower in the case of pooled data, where period averages are rarely longer than 5 years. The variable average value is a dummy equal to one when the primary study uses period averages of the Gini index. The reference category is the adoption of the index at the beginning of the period. The coefficient is positive and significant at the $5 \%$ level.

Recently, Atkinson and Brandolini (2001) have cast doubts on the cross-country comparability of data on income distribution for most of the existing datasets. Deininger and Squire (1996) have proposed the use of a correction factor. ${ }^{17}$ Barro (2000) and Li and Zou (1998) argue that such a solution is too naïve and does not constitute a real solution to the absence of cross-countries comparability in the data. In order to check whether the adjustment rule proposed by Deininger and Squire produces significantly different estimates in the primary studies we have used a dummy variable labelled Expenditure. The dummy is equal to one when in the primary study the authors choose not to correct for the fact that the inequality index is based on a source different from income (i.e., expenditure). The coefficient is not significant, and confirms what is largely found in the empirical literature. ${ }^{18}$

We also investigate the consequence on the parameter estimate of using different samples of countries. The reference category is defined by studies that include both OECD and less developed countries (LDCs) in their sample. Barro (2000) and Galor and Moav (2004) argue that the relationship between inequality and growth is different in rich and poor economies (positive for rich countries and negative for less developed countries). The variables $O E C D$ and $L D C s$ are two distinct dummies that take a value of one when the primary study includes only OECD countries or LDCs in the analysis. Our analysis shows a significant coefficient for both variables

\footnotetext{
17 They suggest adding 6.6 points when the indices are based on expenditure rather than income.

18 Deininger and Squire (1998) and Reheme (2002) estimate the model using both the unadjusted and the adjusted version of the Gini index. Both studies report that the coefficients associated with the Gini coefficient are not substantially different.
} 
and the signs are as expected. When the study focuses on less developed countries the estimates are significantly lower than using a mixed sample of countries, while the studies focusing on industrialized countries only, tend to report a higher value of the coefficient. This result lends support to the hypothesis that the mechanism works in a different direction in rich and poor economies.

We then investigate the impact of the length of the growth period on the effect sizes. If it is true that the negative effect of inequality holds only in the long term, an increase in the length of the growth period is likely to produce estimates that are on average lower. The variable Length of the growth period is a continuous variable that includes the number of years over which the growth rate is calculated (i.e., 25 years, 5 years). As we expect, the longer the growth period, the lower the coefficient associated with the Gini index.

We also check for the impact of two types of conditioning variables widely used in the literature. First, we control for the adequacy of a measure based on income to describe the relationship between inequality and growth. Deininger and Squire (1998) show that while the index based on income is not significant after the inclusion of regional dummies, the same is not true when inequality is measured in terms of asset distribution. In the latter case, the coefficient is negative and significant even after controlling for the regional effects. Castelló (2004) estimates a regression where a measure of human capital inequality and a measure of income inequality are both considered in the same regression. He finds that, while income inequality is not robust to the econometric specification adopted, the negative relationship between human capital inequality and growth persists also when panel data estimations are carried out. We also specifically explore the effect of the introduction of the inclusion of additional measures of inequality in the primary regression. Other definition of inequality is a dummy equal to one when the primary study uses more than one definition of inequality in the regression and zero otherwise. If it is true that income inequality is not fully capable to capture the impact of an unequal distribution of resources on growth, we expect the impact of income inequality to be weaker when the study includes another explanatory variable that control for the effect of other determinants of inequality. The coefficient is not significant and seems to refute the belief that the inconsistency in the empirical results is due to the fact that income inequality is a poor proxy.

It has been claimed that the findings in the literature are sensitive to the inclusion of country-specific dummies. The use of country dummies captures to some extent the effect of country-specific attributes - history, factor endowments and technological differences - in a similar way as the fixed effect model does. Regional effect is a variable with the value of one when the primary studies incorporate regional dummies in the base-regression. The coefficient is 
positive and highly significant. Similarly to the use of a fixed effect estimator in the primary studies the inclusion of country-specific dummies systematically produces highest estimates of the effect size.

As a final test, we check whether there exists a tendency in the literature to report a result that is consistent over time. In the previous section we have observed that publication bias is a potential concern in this literature. What we would like to check is whether there is some kind of time trend in this literature deriving from, for instance, a tendency to publish only well defined studies on the basis of their statistical significance or because their results satisfy preconceived theoretical expectations (for instance a negative impact of inequality on growth). The variable Year of publication is used to control for the presence of a time trend in the publication of the results. It is a continuous variable indicating the year in which the study has been published. The resulting coefficient is not significantly different from zero, indicating that when controlling for observable differences between studies, there is no remaining time trend associated with the magnitude of the reported results.

\section{Conclusions}

Economic theory does not predict unambiguously the direction of the correlation between inequality and economic growth. However, the direction and the magnitude of this correlation is relevant when it comes to policy making and policy evaluation. This recognition has been a driving force behind the empirical investigation of the relationship between income inequality and economic growth, and has by now resulted in the availability of a large number of empirical studies. In the empirical literature, the majority of cross-sectional studies has found a negative correlation between income inequality and growth. However, the negative effect disappears when the models are estimated using panel datasets and associated estimation techniques. So far, no clear conclusions have been derived that lend support to the critique that income inequality might be a poor proxy for wealth inequality, or that the results are crucially dependent on the quality of the data used in the analyses. This paper attempts to make a constructive contribution to the ongoing discussion. We have provided a quantitative synthesis of the empirical literature on inequality and growth using tools offered by meta-analysis, and have investigated whether the variation in the estimated correlation between growth and income inequality can be systematically associated with differences in estimation methods, data quality, the time period covered and the geographical coverage of the primary studies.

The results of the meta-analysis show that the estimated correlation between growth and income inequality are systematically associated with differences in estimation methods, data 
quality and sample coverage. In particular, studies using a fixed-effect model report higher estimates of the effect size, as well as studies based on GMM estimators. The use of fixed-effects estimators or the inclusion of regional-specific dummies in the regressions has a similar effect of reducing the negative impact of inequality on growth in the cross-section estimates, and of accentuating the positive effect in studies based on pooled data. In accordance with Barro (2000), we found that the correlation between growth and income inequality is different in rich as compared to poor countries. The negative impact of an uneven distribution of income is higher in less developed countries. We have also observed that the length of the growth period has an important influence on the outcomes. The longer the length of the growth period (i.e., from 5 to 10 or 20 years), the lower the coefficient estimates of the correlation between income inequality and economic growth. This result supports the assertion that the mechanism at the basis of the relationship between inequality and growth works differently in the short run as compared to the long run. We also found that the quality of data on income inequality is a crucial factor. For data of inferior quality the association of income inequality and economic growth is weaker, regardless whether the correlation is estimated to be positive or negative. Finally, we found that the direction and magnitude of the estimated correlation between growth and income inequality is not significantly affected by the inclusion of additional measures of inequality, such as land inequality or human capital inequality.

There is a tendency in the literature to study the relationship between inequality and growth for samples pooling countries with very different economic, social and institutional characteristics. The analysis of the growth-inequality linkage on a regional basis may, however, be much more informative than the analysis based on worldwide cross-country datasets, as we have seen that some of the variation observed in cross-sections of countries vanishes after allowing for regional effects. A problem when looking at countries with disparate features is that the same model specification might not be relevant for all countries. There might be fundamental differences among countries, for instance in the level of democracy, human rights, type of economy, education system, etc., which does not make it reasonable to expect that one model holds for all countries. Limiting the scope of the study to regions within the same country, or to countries with similar socio-economical characteristics would definitely help to shed new light on the relationship between inequality and growth. 


\section{References}

Ashenfelter O, Harmon C, and Oosterbeek H (1999) A Review of Estimates of the Schooling/Earnings Relationship, with Tests for Publication Bias, Labour Economics, 6: 453-70.

Atkinson A, and Brandolini A (2001) Promise and Pitfalls in the Use of "Secondary" Datasets: Income Inequality in OECD Countries as a Case Study, Journal of Economic Literature, 39 (3): 771-99.

Abreu M, de Groot HLF, and Florax RJGM (2005) Meta-Analysis of $\beta$-Convergence: The Legendary 2\%, Journal of Economic Surveys, 19 (3): 389-420.

Aghion P, Caroli E, and Garcia-Penalosa C (1999) Inequality and Economic Growth: The Perspective of the New Growth Theories, Journal of Economic Literature, 37 (4): 1615-60.

Alesina A, and Rodrik D (1994) Distributive Politics and Economic Growth, Quarterly Journal of Economics, 109 (2): 465-90.

Alesina A, and Perotti R (1996) Income Distribution, Political Instability, and Investment, European Economic Review, 81 (5): 1170-89.

Arellano M, and Bond S (1991) Some Tests of Specification for Panel Data: Monte Carlo Evidence and an Application to Employment Equations, Review of Economic Studies, 58 (2): 277-97.

Arellano M, and Bover O (1995) Another Look at the Instrumental-Variable Estimation of ErrorComponents Models, Journal of Econometrics, 68: 29-51.

Banerjee AV, and Duflo E (2003) Inequality and Growth: What Can the Data Say?, Journal of Economic Growth, 8: 267-99.

Barro RJ (2000) Inequality and Growth in a Panel of Countries, Journal of Economic Growth, 5: 5-32.

Bateman IJ, and Jones AP (2003) Contrasting Conventional with Multi-Level Modeling Approaches to Meta-Analysis: Expectation Consistency in U.K. Woodland Recreation Values, Land Economics, 79 (2): 235-58.

Beacon H, Clarke R, and Frost H (1999) Use of Hierarchical Models for Meta-Analysis: Experience in the Metabolic Ward Studies of Diet and Blood Cholesterol, Statistics in Medicine, 18: 1657-76.

Benabou R (1996) Inequality and Growth, NBER Working Paper no. 5658, Cambridge, MA.

Bertola G (1993) Factor Shares and Savings in Endogenous Growth, American Economic Review, 83 (5): 1184-98.

Button KJ (1995) What Can Meta-Analysis Tell Us About the Implications of Transport?, Regional Studies, 29: 507-17.

Button KJ, and Kerr J (1996) The Effectiveness of Traffic Restraint Policies, A Simple Meta Regression Model, International Journal of Transport Economics, 23: 213-25.

Bijmolt THA, and Pieters RGM (1999) Meta-Analysis in Marketing when Studies Contain Multiple Measurements, Marketing Letters, 12 (2): 157-69.

Brander LM, Florax RJGM, and Vermaat JE (2006) The Empirics of Wetland Valuation: A Comprehensive Summary and a Meta-Analysis of the Literature, Environmental and Resource Economics, 33 (2) 223-50,

Brouwer R, Langford IJ, Bateman IJ, and Turner R.K (1999) A Meta-Analysis of Wetland Contingent Valuation Studies, Regional Environmental Change, 1 (1): 47-57.

Button KJ, and Rietveld P (2000) A Meta-Analysis of the Impact of Infrastructure Policy on Regional Development, in: H. Kohno, P. Nijkamp and J. Poot (eds), Regional Cohesion and Competition in the Age of Globalization, Cheltenham: Edward Elgar.

Card D, and Krueger AB (1995) Time-Series Minimum Wage Studies: A Meta-Analysis, American Economic Review, 85: 238-43.

Castello A (2004) A Reassessment of the Relationship Between Inequality and Growth: What Human Capital Inequality data Say?, IVIE Working Paper no. 15.

Clarke GRG (1995) More Evidence on Income Distribution and Growth, Journal of Development Economics, 47: 403-27.

Cowell FA (1995), Measuring Inequality, second edition, London: Prentice Hall.

de Blaeij A, Florax, RJGM, Rietveld P, and Verhoef ET (2003). The Value of Statistical Life in Road Safety: A Meta-Analysis, Accident Analysis and Prevention, 35: 973-86.

de la Croix, D. and Doepke, M. (2003) Inequality and growth: Why Differential Fertility Matters, American Economic Review, 3 (4): 1091-113.

Deininger K, and Squire L (1996) A New data set Measuring Income Inequality, World Bank Economic Review, 10 (3): 563-91. 
Deininger K, and Squire L (1998) New Ways of Looking at Old Issue: Inequality and Growth, Journal of Development Economics, 57: 259-87

Deininger K, and Olinto P (1998) Asset Distribution, Inequality, and Growth, Policy Research Working Paper, World Bank no. 2375, Washington, D.C.

Egger M, Smith GD, Scheider M, and Minder C (1997) Bias in Meta-Analysis Detected by Simple Graphical Test, British Medical Journal, 316: 629-34.

Feldstein M, and Horioka C (1980) Domestic Saving and International Capital Flows, Economic Journal, 90: 314-329.

Florax RJGM (2002) Accounting for Dependence among Study Results in Meta-Analysis: Methodology and Applications to the Valuation and Use of Natural Resources, Dept. of Spatial Economics, Vrije Universiteit, Research Memorandum no. 2002-5, Amsterdam.

Forbes KJ (2000) A Reassessment of the Relationship between Inequality and Growth, American Economic Review, 90 (4): 869-87.

Galor O, and Zang H (1997) Fertility, Income Distribution, and Economic Growth: Theory and CrossCountry Evidence, Japan and the World Economy, 9 (2): 197-229.

Galor O, and Zeira J (1993) Income Distribution and Macroeconomics, Review of Economic Studies, 60 (1): $35-52$.

Galor O, and Moav O (2004) From Physical to Human Capital Accumulation: Inequality and the Process of Development, Review of Economic Studies, 71: 1001-26.

Glass GV (1976) Primary, Secondary, and Meta-Analysis of Research, Educational Researcher, 5 (10): 3-8.

Goldstein H, Yang M, Omar R, Turner R, and Thompson S (2000) Meta-Analysis Using Multilevel Models with an Application to the Study of Class Size Effects, Applied Statistics, 49 (3): 399-412.

Goldstein H (1995) Multilevel Statistical Models, Second Ed., London: Edward Arnold.

Gorg H, and Strobl E (2001) Multinational Companies and Productivity Spillovers: a Meta-Analysis, Economic Journal, 111: 723-39.

Greene WH (2000). Econometric Analysis, Fourth Ed., Upper Saddle River, New Jersey: Prentice Hall International.

Hedges LV, and Olkin I (1985) Statistical Methods for Meta-Analysis, New York: Academic Press.

Kuznets S (1955) Economic Growth and Income Inequality, American Economic Review, 45: 1-28.

Li H, and Zou H (1998) Income Inequality is not Harmful for Growth: Theory and Evidence, Revien of Development Economics, 2 (3): 318-34.

Longhi S, Nijkamp P, and Poot J (2005) A Meta-Analytic Assessment of the Effect of Immigration on Wages, Journal of Economic Surveys, 19 (3): 451-77.

Mirrlees JA (1971) An Exploration in the Theory of Optimum Income Taxation, Review of Economic Studies 38: 175-208.

Nahuis R, and de Groot HLF (2003) Rising Skill Premia: You Ain't Seen Nothing Yet?, CPB Discussion Paper, no. 20, The Hague.

Odedokun MO, and Round JI (2001) Determinants of Income Inequality and its Effects on Economic Growth, WIDER Discussion Paper no. 2001/103.

Panizza U (2002) Income Inequality and Economic growth: Evidence form American Data, Journal of Economic Growth, 7: 25-41.

Partridge MD (2005) Does Income Distribution Affect U.S. State Economic Growth? Journal of Regional Science, 45 (2): 363-94.

Persson T, and Tabellini G (1994) Is Inequality Harmful for Growth?, American Economic Review, 84 (3): 600-21.

Raudenbush SW, and Bryk AS (2002) Hierarchical Linear Models: Applications and Data Analysis Methods, 2nd ed., Sage Publications.

Roberts C, and Stanley TD (2005) Meta-Regression Analysis: Issues of Publication Bias in Economics, Oxford: Blackwell Publishing.

Rose AK, and Stanley TD (2004) A Meta-Analysis of the Effect of Common Currencies on International Trade, Journal of Economic Surveys, 19 (3): 347-65.

Rosenthal R (1991). Meta-Analytic procedures for Social Research, Revised Eds., Newbury Park: Sage.

Rutter CM, and Gatsonis CA (2001) A Hierarchical Regression Approach to Meta-Analysis of Diagnostic Test Accuracy Evaluations, Statistics in Medicine, 20: 2865-84.

Stanley TD (1998) New wine in Old Bottles: A meta-analysis of Ricardian equivalence, Southern Economic Journal 64: 713-27. 
Stanley TD (2001) Wheat from Chaff: Meta-Analysis as Quantitative Literature Review, Journal of Economic Perspectives, 15: 131-50.

Stanley TD (2004) Does Unemployment Hysteresis Falsify the Natural Rate Hypothesis? A MetaRegression Analysis, Journal of Economic Surveys, 18 (4): 589-612.

Stanley TD (2005) Beyond Publication Bias, Journal of Economic Surveys, 19: 309-337

Stanley TD, and Jarrell SB (1989) A Meta-Regression Analysis: a Quantitative Method of Literature Surveys, Journal of Economic Surveys, 3: 54-67.

Sutton AJ, Abrams KR, Jones DR, Sheldon TA, and Song F (2000), Methods for Meta-Analysis in Medical Research, New York: Wiley.

Szekely M, and Hilgert M (1999) What's Behind the Inequality We Measure: An Investigation Using Latin American Data, Inter-American Development Bank no. 409.

Temple J (1999) The New Growth Evidence, Journal of Economic Literature, 37 (1): 112-56.

Travisi MC, Florax RJGM, and Nijkamp P (2005) A Meta-Analysis of the Willingness to Pay for Reductions in Pesticide Risk Exposure, European Review of Agricultural Economics, 32 (4): 441-67.

van den Bergh JCJM, Button KJ, Nijkamp P, and Pepping, GC (1997), Meta-Analysis in Environmental Economics, AH Dordrecht, The Netherlands: Kluwer Academic Publishers.

Voitchovsky S (2005) Does the Profile of Income Inequality Matter for Economic Growth? Distinguishing Between the Effects of Inequality in Different Parts of the Income Distribution, Journal of Economic Growth, 10 (3): 273-96.

Wardman M (2001) A review of British evidence on time and service quality valuations, Transportation Research, Part E: Logistics and Transportation Review 37: 107-28.

Zak PJ, and Knack S (2001) Trust and Growth, Economic Journal, 111: 295-321. 


\section{Appendix. List of case studies included in the database}

Alesina A, and Rodrik D (1994) Distributive Politics and Economic Growth, Quarterly Journal of Economics, 109 (2): 465-90.

Banerjee AV, and Duflo E (2003) Inequality and Growth: What Can the Data Say?, Journal of Economic Growth, 8: 267-99.

Barro RJ (2000) Inequality and Growth in a Panel of Countries, Journal of Economic Growth, 5: 5-32.

Castello A, and Domenech R (2002) Human Capital Inequality and Economic Growth: Some New Evidence, Economic Journal, 112: 187-200.

Castello A (2004) A Reassessment of the Relationship Between Inequality and Growth: What Human Capital Inequality data Say?,IVIE Working Paper no. 15.

Clarke GRG (1995) More Evidence on Income Distribution and Growth, Journal of Development Economics, 47: 403-27.

de la Croix D, and Doepke M (2003) Inequality and Growth: Why Differential Fertility Matters, American Economic Review, 3 (4): 1091-113.

Deininger K, and Squire L (1998) New Ways of Looking at Old Issue: Inequality and Growth, Journal of Development Economics, 57: 259-87

Deininger K, and Olinto P (1998) Asset Distribution, Inequality, and Growth, Policy Research Working Paper, World Bank no. 2375, Washington D.C.

Figini P (1999) Inequality and Growth Revisited, Trinity College Paper Series no. 99/2.

Forbes KJ (2000) A Reassessment of the Relationship between Inequality and Growth, American Economic Review, 90 (4): 869-87.

Gylfason T, and Zoega G (2003) Inequality and Economic Growth: Do Natural Resources Matter? In T. Eicher and S. Turnovsky (eds), Inequality and Growth: Theory and Policy Implications, Cambridge, MA: MIT Press.

Keefer P, and Knack S (2002) Polarization, Politics and Property Rights: Links Between Inequality and Growth, Public Choice, 111: 127-54.

Knell M (1999) Social Comparisons, Inequality, and Growth, Journal of Institutional and Theoretical Economics, 155 (4): 664-95.

Knowles S (2005) Inequality and Economic Growth: The Empirical Relationship Reconsidered in the Light of Comparable Data, Journal of Development Studies, 41 (1): 135-159.

$\mathrm{Li} \mathrm{H}$, and Zou H (1998) Income Inequality is not Harmful for Growth: Theory and Evidence, Revien of Development Economics, 2 (3): 318-34.

Mbabazi J, Morrissey O, and Milner C (2001) Are Inequality and Trade Liberalization Influences on Growth and Poverty?, WIDER Discussion Paper no. 2001/132.

Odedokun MO, and Round JI (2001) Determinants of Income Inequality and its Effects on Economic Growth, WIDER Discussion Paper no. 2001/103.

Panizza U (2002) Income Inequality and Economic growth: Evidence form American Data, Journal of Economic Growth, 7: 25-41.

Persson T, and Tabellini G (1994) Is Inequality Harmful for Growth?, The American Economic Review, 84 (3): 600-21.

Rehme, G. (2002) Education, Economic Growth and Personal Income Inequality Across (Rich) Countries, Luxembourg Income Study Working Paper no. 300.

Voitchovsky S (2005) Does the Profile of Income Inequality Matter for Economic Growth? Distinguishing Between the Effects of Inequality in Different Parts of the Income Distribution, Journal of Economic Growth, 10 (3): 273-96. 


\section{Tables and Figures}

Table 1. References, number of estimates, structure of the data and average estimates for the studies in the sample.

\begin{tabular}{|c|c|c|c|c|}
\hline Studya & $\begin{array}{c}\text { Type of } \\
\text { publication }\end{array}$ & $\begin{array}{c}\text { Nr. of } \\
\text { estimates }\end{array}$ & Data $^{b}$ & $\begin{array}{l}\text { Average } \\
\text { effect size }\end{array}$ \\
\hline Alesina and Rodrik (1994) & $\mathrm{J}$ & 12 & cs & -0.064 \\
\hline Banerjee and Duflo (2003) & $\mathrm{J}$ & 8 & $\mathrm{p}$ & 0.216 \\
\hline Barro (2000) & $\mathrm{J}$ & 6 & $\mathrm{p}$ & -0.013 \\
\hline Clarke (1995) & $\mathrm{J}$ & 13 & cs & -0.081 \\
\hline Castelló (2004) & WP & 2 & $\mathrm{cs}, \mathrm{p}$ & 0.041 \\
\hline Castelló and Domenech (2000) & $\mathrm{J}$ & 10 & $\mathrm{cs}$ & 0.036 \\
\hline Deininger and Olinto (2000) & WP & 9 & $\mathrm{p}$ & 0.132 \\
\hline Deininger and Squire (1998) & $\mathrm{J}$ & 10 & $\mathrm{cs}$ & -0.027 \\
\hline de la Croix and Doepke (2003) & $\mathrm{J}$ & 6 & cs & 0.017 \\
\hline Figini (1999) & WP & 42 & cs & -0.058 \\
\hline Forbes $(2000)$ & $\mathrm{J}$ & 9 & $\mathrm{cs}, \mathrm{p}$ & 0.087 \\
\hline Gylfason and Zoega (2002) & $\mathrm{J}$ & 1 & $\mathrm{cs}$ & -0.040 \\
\hline Keefer and Knack (2000) & $\mathrm{J}$ & 2 & cs & -0.067 \\
\hline Knell (1998) & $\mathrm{J}$ & 3 & $\mathrm{cs}$ & -0.044 \\
\hline Knowles (2001) & $\mathrm{J}$ & 20 & cs & -0.020 \\
\hline $\mathrm{Li}$ and Zou (1998) & $\mathrm{J}$ & 20 & $\mathrm{cs}, \mathrm{p}$ & 0.051 \\
\hline Mbabazi et al. (2001) & WP & 15 & $\mathrm{cs}, \mathrm{p}$ & -0.014 \\
\hline Odedokun and Round (2001) & $\mathrm{J}$ & 4 & $\mathrm{p}$ & -0.084 \\
\hline Panizza (2002) & $\mathrm{J}$ & 35 & $\mathrm{cs}, \mathrm{p}$ & -0.015 \\
\hline Persson and Tabellini (1994) & $\mathrm{J}$ & 1 & $\mathrm{cs}$ & -0.055 \\
\hline Rehme (2002) & WP & 19 & cs & -0.068 \\
\hline Voitchovsky (2005) & $\mathrm{J}$ & 13 & $\mathrm{p}$ & -0.043 \\
\hline Totalc & & 254 & & -0.005 \\
\hline
\end{tabular}

a Between brackets is the year of publication of the study; $J$ for studies published in journals, WP for working papers.

${ }^{\mathrm{b}} c s$ is for studies based on cross-section data, $p d$ is for studies based on pooled data.

c This is the sum for the third column and the average value for the last column. The average is calculated over the entire sample of 241 observations. 
Table 2: Meta-regression results.

\begin{tabular}{llcc}
\hline \multicolumn{1}{c}{ Study characteristics ${ }^{\mathrm{a}}$} & Moderator variables & $\begin{array}{c}\text { Random effect } \\
\text { model }\end{array}$ & $\begin{array}{c}\text { Hierarchical linear } \\
\text { model }\end{array}$ \\
\hline \hline & & & \\
$\begin{array}{l}\text { Structure of the data } \\
\text { (Cross-section) }\end{array}$ & Pooled & $0.032^{* * *}$ & $0.066^{* * *}$ \\
& & $(0.009)$ & $(0.014)$ \\
& & & \\
Estimation method & Fixed effects & $0.063^{* * *}$ & $0.051^{* * *}$ \\
(OLS) & Random effects & $(0.008)$ & $(0.010)$ \\
& & -0.123 & $-0.047^{* * *}$ \\
& Endogeneity & $(0.013)$ & $(0.016)$ \\
& & $0.029 * * *$ & -0.006 \\
& & $(0.006)$ & $(0.010)$
\end{tabular}

Characteristics of data on income distribution

Dataset on income distribution (Deininger and Squire)

Quality of data

(High)

Dynamic of the inequality index

(Initial value )

Source of income data

(Income)

Sample of countries

(OECD and LDCs)
Other dataset

Other dataset* ${ }^{*}$-s

High and low

Low

Average value

Expenditure

OECD

LDCs

$$
\begin{aligned}
& -0.051 \text { *** } \\
& (0.009) \\
& 0.095^{* * *} \\
& (0.009)
\end{aligned}
$$$$
-0.078 * * *
$$$$
(0.017)
$$$$
0.104 * * *
$$$$
\text { (0.014) }
$$

$-0.049 * * *$

$0.029 *$

(0.006)

(0.016)

$-0.018$

$-0.036 *$

(0.019)

(0.020)

$-0.008$

(0.006)

$0.064 * *$

(0.030)

$-0.001$

0.001

(0.003)

(0.004) 
Table 2. continued

\begin{tabular}{|c|c|c|c|}
\hline Study characteristics ${ }^{a}$ & Moderator variables & $\begin{array}{c}\text { Random effect } \\
\text { model }\end{array}$ & $\begin{array}{c}\text { Hierarchical linear } \\
\text { model }\end{array}$ \\
\hline Time horizon & $\begin{array}{l}\text { Length of the growth } \\
\text { period } t\end{array}$ & $\begin{array}{l}-0.002^{* * *} \\
(0.001)\end{array}$ & $\begin{array}{l}-0.002 * * * \\
(0.001)\end{array}$ \\
\hline & Initial year ${ }^{\dagger}$ & $\begin{array}{l}-0.002 * * * \\
(0.001)\end{array}$ & $\begin{array}{r}-0.000 \\
(0.0004)\end{array}$ \\
\hline Conditioning variables & $\begin{array}{l}\text { Other definitions } \\
\text { of inequality }\end{array}$ & $\begin{array}{r}0.005 \\
(0.004)\end{array}$ & $\begin{array}{r}0.001 \\
(0.005)\end{array}$ \\
\hline & Regional dummies & $\begin{array}{l}0.054 * * * \\
(0.005)\end{array}$ & $\begin{array}{l}0.019 * * * \\
(0.006)\end{array}$ \\
\hline Publication trend & Year of Publication ${ }^{\dagger}$ & $\begin{array}{l}-0.000 \\
(0.000)\end{array}$ & $\begin{array}{l}-0.000 \\
(0.000)\end{array}$ \\
\hline Constant & & $\begin{array}{l}4.367 * * * \\
(0.832)\end{array}$ & $\begin{array}{r}0.866 \\
(1.076)\end{array}$ \\
\hline
\end{tabular}

Level-1 obs (nr. of estimates): 254

Level-2 obs (nr. of studies): 22

a Between brackets is the reference category.

The dependent variable is the parameter of the Gini coefficient estimated from primary studies. Standard errors in parenthesis. The statistic significance of the parameters is indicated by ***, **, *, referring respectively to the $1 \%, 5 \%$ and $10 \%$ level. All moderator variables enter the regression as dummies, except those labelled with a "†" which are continuous variables 


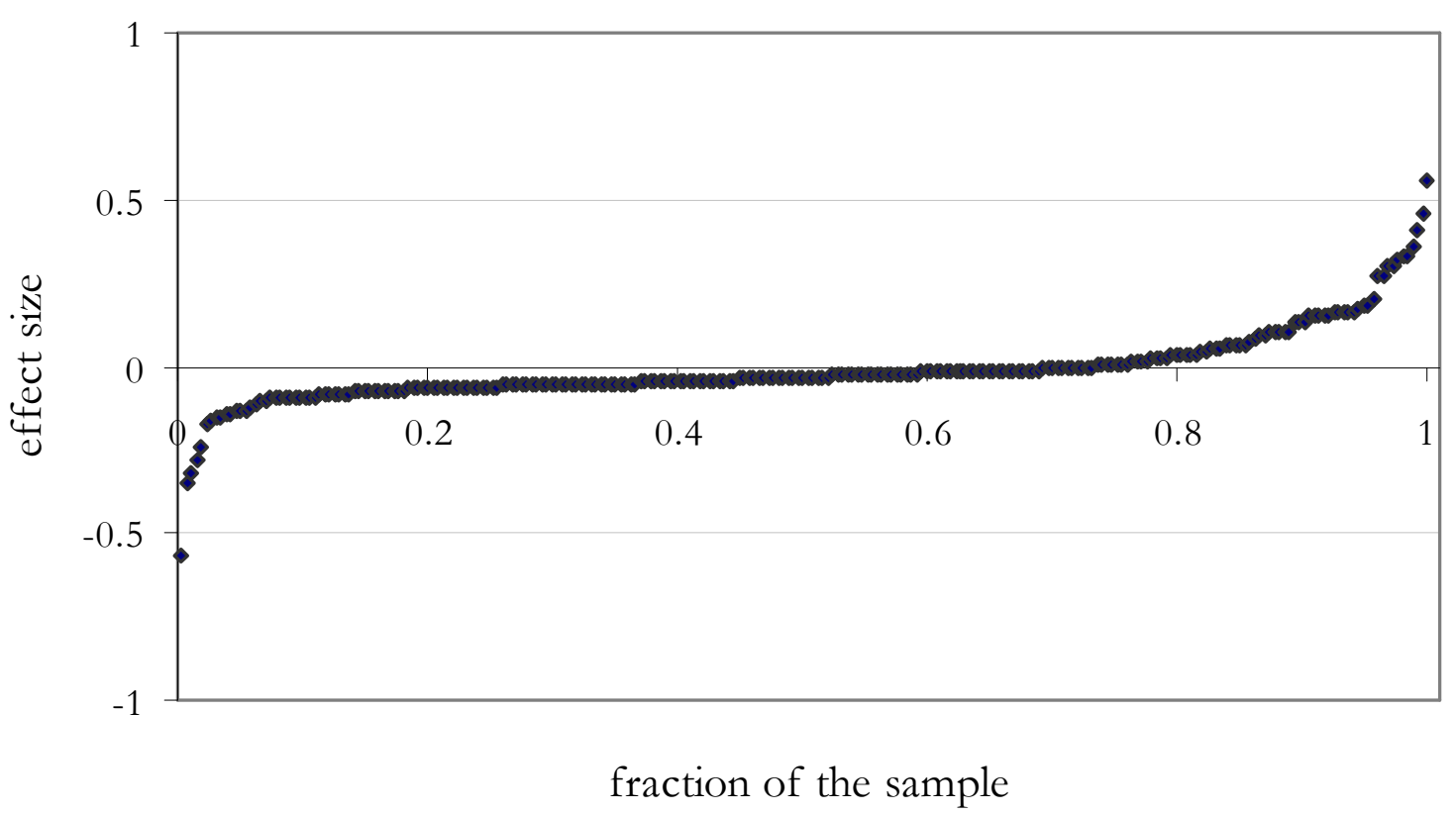

Figure 1. Frequency distribution of the estimated effect of inequality on growth

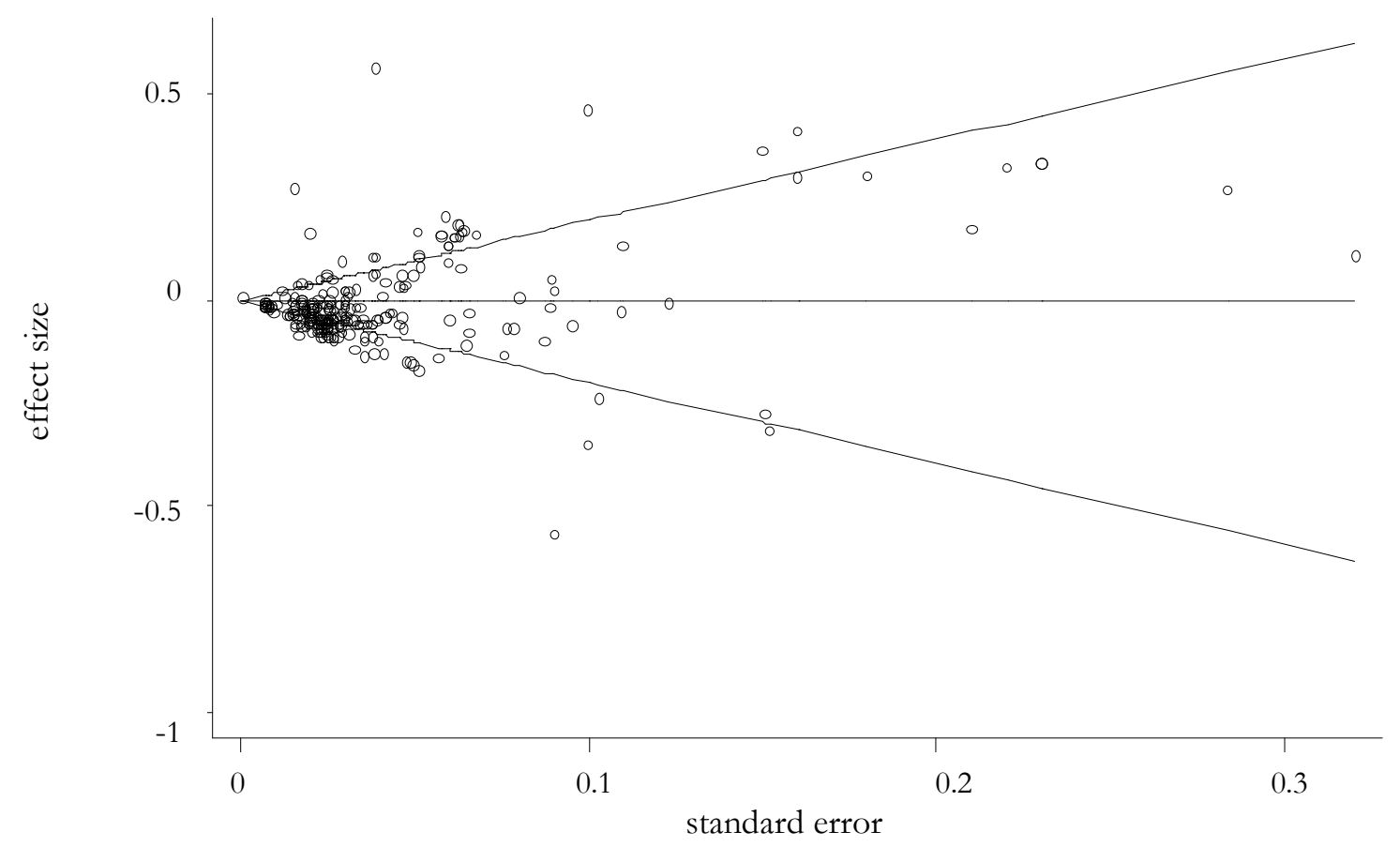

Figure 2. Funnel plot of 254 estimated coefficients of the impact of inequality upon growth 